\title{
Parasitología molecular
}

\section{Protozoología}

\section{Determinación de la expresión de glucosamina-6-fosfato-isomerasa y la glucoproteína de Jacob en el quiste y su diferencia en el trofozoíto de Entamoeba histolytica}

María del Pilar Crisóstomo-Vázquez, Leticia EligioGarcía Víctor Alberto Maravelez-Acosta, Patricia

Antonio-Cruz, Andrés Flores-Luna, René Sánchez-de la Luz , Enedina Jiménez-Cardoso

Laboratorio de Investigación en Parasitología, Hospital Infantil de México Federico Gómez, México D.F., México

Introducción. Entamoeba histolytica es un protozoario que presenta dos formas; el quiste responsable de la transmisión y el trofozoíto que produce la enfermedad. La formación del quiste está asociada con la expresión de los genes glucosamina-6-fosfato isomerasa $(g n 6 p /)$, y la glicoproteína de Jacob ( $g / y J)$ que participan en la formación del polímero de $\mathrm{N}$-acetil glucosamina, componente principal de la pared de quitina.

Objetivo. Determinar la expresión de los genes de glucosamina-6-fosfato-isomerasa y la proteína de Jacob en los quistes y trofozoítos de E. histolytica obtenidos de aislamientos de pacientes con amibiasis intestinal.

Material y métodos. Se obtuvieron trofozoítos de E. histolytica a partir de quistes procedentes de pacientes. En el ensayo de validación se utilizó la cepa E. histolytica HM-1. Se extrajo ARN total de los quistes y trofozoítos por el método de trizol y se purificó con el kit RNAqueous. Se llevó a cabo RT-PCR en tiempo real con las sondas correspondientes a los genes gn6pl y glyJ de E. histolytica

Resultados. Se correlacionó el número de copias de los tres genes amplificados por triplicado. En el ensayo de validación se obtuvieron pendientes negativas con valores de 3,5 y un coeficiente de correlación mayor de 0,99. La expresión de los genes gn6pl y glyJ en la etapa de trofozoíto, presento un valor promedio de 3,5 en cinco de las ocho muestras analizadas y, en la etapa de quiste, fue de 1,2 en todas las muestras. El control positivo presentó un valor de 5 para el gen gn6pl y de 9,8 para el gen glyJ.
Conclusiones. En la etapa de quiste no hubo expresión de los genes gn6ply glyJy en la etapa de trofozoíto sí. Es necesario sincronizar los cultivos de trofozoítos para conocer si la expresión de los genes gn6pl y glyJ está relacionada con la reciente transformación de la etapa quística a trofozoíto.

\section{Papel de los linfocitos $T$ reguladores en la patogénesis y curación de la leishmaniasis cutánea crónica causada por Leishmania (Viannia)}

Daniel Rodríguez-Pinto, Adriana Navas, Víctor Blanco, Daniel Garcerant, Nancy Saravia

Centro Internacional de Entrenamiento e Investigaciones Médicas, Cali, Colombia

Introducción. La leishmaniasis cutánea crónica causada por Leishmania (Viannia) se caracteriza por una potente respuesta inflamatoria inadecuadamente regulada. Los linfocitos $T$ reguladores pueden contribuir en el desarrollo de la enfermedad y su resolución al mitigar la respuesta inmunitaria específica para el parásito.

Materiales y métodos. Se extrajeron muestras de sangre periférica de 12 individuos con infección asintomática y 14 pacientes con leishmaniasis cutánea crónica antes y después de tratamiento con antimonio pentavalente. La frecuencia de linfocitos $T$ reguladores determinó por citometría de flujo y su capacidad para inhibir respuestas efectoras (proliferación y secreción de interferón- $\gamma$ ) de una manera antígeno-específica, se determinó in vitro por cultivo simultáneo de linfocitos $C D 4^{+} C D 25^{+}$y CD4 ${ }^{+}$CD25

Resultados. Los pacientes con leishmaniasis cutánea crónica presentaron una frecuencia significativamente mayor de linfocitos $\mathrm{CD}_{4}{ }^{+} \mathrm{CD} 25^{\mathrm{h}} \mathrm{FoxP} 3^{+}$, en relación a individuos asintomáticos $(0,9 \% \mathrm{Vs}$. $0,4 \%$ ), pero sus linfocitos $\mathrm{CD}^{+}{ }^{+} \mathrm{CD} 25^{+}$tuvieron una capacidad menor de inhibir la secreción de interferón- $\gamma$ (48 \% Vs. $80 \%$ de inhibición). Al final del tratamiento, los pacientes presentaron un aumento significativo en la frecuencia de linfocitos $\mathrm{CD}^{+}{ }^{+} \mathrm{CD} 25^{\text {hi }} \mathrm{CD} 127^{-}$(de 1,5\% a 2,3\%) y en la capacidad inhibitoria de sus linfocitos $\mathrm{CD} 4^{+} \mathrm{CD} 25^{+}$ (de $21,9 \%$ a $46,5 \%$ en proliferación y de 47,2 $\%$ a $81,3 \%$ en secreción de interferón- $\gamma$ ). Estos 
incrementos coincidieron con la curación de las lesiones cutáneas.

Conclusiones. Mientras un aumento de un subgrupo de linfocitos $\mathrm{T}$ reguladores $\mathrm{FoxP}^{+}$se asocia con la vulnerabilidad ante la leishmaniasis cutánea crónica, la inducción de otro subgrupo CD127 y una mejor capacidad reguladora después del tratamiento, se asocian con la curación de la enfermedad.

Financiación. Colciencias, proyecto \# 2652229 459-21594; Fogarty International Center, \# D43 TW006589; y National Institute of Allergy and Infectious Diseases, ICDR, \#U19 AI065866.

Variación genética de Pfmsp1, Pfmsp2, Pfglurp y Pvmsp3 $\alpha$ en aislamientos de Plasmodium falciparum y Plasmodium vivax obtenidos de mujeres gestantes, Antioquia y Córdoba, 2011

Eliana Arango, Jaime Carmona-Fonseca, Amanda Maestre

Grupo Salud y Comunidad, Facultad de Medicina, Universidad de Antioquia, Medellín, Colombia

Introducción. Los genes que codifican las proteínas MSP1, MSP2 y GLURP, han sido ampliamente usados para evaluar la diversidad genética de Plasmodium falciparum, mientras que para $P$. vivax se ha utilizado el gen $P v m s p 3 \alpha$.

Este estudio evaluó la variabilidad genética de estos cuatro marcadores en los parásitos aislados de gestantes residentes en los municipios de Turbo y Puerto Libertador, endémicos para paludismo.

Materiales y métodos. Como proyecto anidado en otro macroproyecto, se seleccionaron 40 gestantes con infección única por $P$. falciparum o $P$. vivax (20 por especie), confirmada por PCR anidada. Para el análisis de los genes Pfmsp1, Pfmsp2 y Pfglurp, se usó el protocolo del MR4 (2008) y para Pvmsp3 $\alpha$ se usó el protocolo de Zakeri et al., 2006.

Resultados. Los promedios de edad y parasitemia fueron 22 años y 6.506 parásitos/ $\mu \mathrm{l}$, sin diferencias entre especies. El genotipo para Pfmsp1 fue igual en los 20 aislamientos (MAD20 positivos [alelo de 150 pb] y RO33 - K1 negativos). Lo mismo sucedió con Pfmsp2: todas las muestras fueron IC positivas (alelo de 500 pb) y FC negativas. Del gen Pfglurp se encontraron cuatro alelos: $45 \%$ (9/20) tenían el alelo de 800 pb, $30 \%(6 / 20)$ tenían el alelo de 700 pb, $15 \%$ (3/20) tenían el alelo de 1.100 pb, sólo $5 \%(1 / 20)$ presentó el alelo de 900 pb y otro $5 \%$ tenía los alelos de 700 y 800 pb.

Del Pvmsp3 $\alpha$ se encontró el alelo de tipo A en 70
$\%(14 / 20)$, el alelo de tipo C en $20 \%(4 / 20)$ y el alelo de tipo B en $5 \%$ (1/20); otra muestra presentó juntos los alelos $\mathrm{B}$ y $\mathrm{C}$. En total, se encontraron seis patrones de restricción diferentes con las enzimas Alul y Hhal.

Conclusiones. De los tres marcadores evaluados en $P$. falciparum, solamente Pfglurp mostró variación. La diversidad genética de $P$. vivax fue mayor que la de $P$. falciparum.

\section{Genotipificación de aislamientos de Giardia intestinalis obtenidos de humanos y perros, mediante análisis de los genes gdh, tpi y b-giardina}

Enedina Jiménez, Leticia Eligio-García, María del Pilar Crisóstomo-Vázquez, Víctor A. Maravelez-Acosta, Apolinar Cano-Estrada, Adrián Cortés-Campos Laboratorio de Investigación en Parasitología, Hospital Infantil de México FG, México D.F., México

Introducción. De los siete genotipos de Giardia intestinalis reconocidos a nivel mundial, se considera que sólo A y B infectan a humanos, mientras que los genotipos $C$ y $D$ se encuentran en perros. Sin embargo, los genotipos $A$ y $B$ se han identificado eventualmente en perros en regiones endémicas. El genotipo $E$ se ha aislado de cerdos y de mamíferos de granja, en gatos se ha clasificado el genotipo $\mathrm{F}$ y los roedores pertenecen al genotipo G. Estos resultados se han obtenido mediante diferentes estrategias moleculares, que no siempre presentan una correlación de $100 \%$ entre ellas. Por ello, la determinación del genotipo de Giardia es importante tanto para establecer la correlación entre síntomas clínicos y genotipos, como para analizar factores epidemiológicos y zoonóticos.

En este trabajo, mediante PCR-restricción de los genes tpi, gdh y b-giardina, se hizo la clasificación genotípica de aislamientos de Giardia obtenidos de humanos y de perro.

Material y métodos. Se extrajo el ADN de heces de perros y humanos infectados con Giardia. Se llevó a cabo la PCR de los genes gdh, b-giardina y tpi, y posteriormente, se determinaron los patrones de restricción con las enzimas Bsp HI, Hae III y Rsa I, respectivamente. Los aislamientos se clasificaron en su respectivo genotipo.

Resultados. Las muestras analizadas, 11 de perro y 19 de humano, se clasificaron como Al. Las 30 muestras pertenecen al genotipo $\mathrm{Al}$, de acuerdo con su patrón de restricción, independientemente de su huésped de origen. La genotipificación mostró el mismo resultado con los tres genes estudiados. 
Conclusión. Aunque se ha reportado la presencia de aislamientos del genotipo A - B en infecciones humanas y $C$ - $D$ en muestras de perro, en este trabajo se encontraron sólo pertenecientes al genotipo Al, independientemente del origen y del gen utilizado para su genotipificación.

\section{Evaluación de proteínas que interactúan con la "supuesta" subunidad reguladora de la proteína cinasa dependiente de cAMP de Trypanosoma evansi \\ Floritza Bustamante ${ }^{1,2}$, Victoria Navas $^{3}$, Juan Carlos \\ Martínez ${ }^{1}$, José Bubis ${ }^{2}$ \\ 1 Fundación Instituto de Estudios Avanzados, Caracas, Venezuela \\ 2 Departamento de Biología Celular, Universidad Simón Bolívar, Caracas, Venezuela \\ 3 Escuela de Biología, Facultad de Ciencias, Universidad Central de Venezuela, Caracas, Venezuela}

Introducción. Poco se conoce acerca de la proteína cinasa dependiente de AMPc en tripanosomatídeos. En el presente trabajo se inicia el estudio del papel de la "supuesta" subunidad reguladora $(R)$ de la proteína cinasa dependiente de AMPc de Trypanosoma evansi.

Materiales y métodos. A partir de la base de datos del genoma de $T$. brucei, se obtuvo la secuencia del gen que codifica para la "supuesta" subunidad $\mathrm{R}$ de la proteína cinasa dependiente de AMPc. Se diseñaron oligonucleótidos apropiados para amplificar por PCR el gen correspondiente, a partir del ADN genómico de T. evansi. Este gen fue modificado añadiéndole ocho codones para histidinas en su extremo 3', y se insertó en un vector para su expresión en bacterias. La proteína se purificó mediante cromatografía a través de una columna de níquel. El tamaño de la proteína se midió por cromatografía de exclusión molecular, y su actividad enlazadora de nucleótidos cíclicos se determinaó mediante ensayos de diálisis por equilibrio usando $\left[{ }^{3} \mathrm{H}\right]$ cAMP y $\left[{ }^{3} \mathrm{H}\right]$ cGMP. A fin de analizar las proteínas que interactúan con la "supuesta" subunidad $\mathrm{R}$ de la proteína cinasa dependiente de AMPc, la proteína unida a la columna de níquel se incubó con un extracto de $T$. evansi. Las bandas unidas a la subunidad $R$ se identificaron por electroforesis en geles de poliacrilamida en presencia de SDS.

Resultados. La "supuesta" subunidad R correspondió a una proteína monomérica de 57 $\mathrm{kDa}$ de peso molecular. El ensayo de diálisis por equilibrio demostró que la proteína no presenta la capacidad de enlazar nucleótidos cíclicos. Se identificaron bandas polipeptídicas de $25 \mathrm{kDa}, 40$ kDa, y 100 kDa en el homogenato del parásito que parecen interactuar con la "supuesta" subunidad $R$ de la proteína cinasa dependiente de AMPc de $T$. evansi.

Conclusiones. Estos resultados permiten concluir que la subunidad $R$ es una proteína monomérica que no enlaza nucleótidos cíclicos y que está involucrada en interacciones con otras proteínas del parásito.

\section{Obtención de anticuerpos específicos para la proteína TMK96 de Entamoeba histolytica, con aplicación diagnóstica}

Enedina Jiménez-Cardoso, María del Pilar CrisóstomoVázquez, Leticia Eligio-García, Víctor Alberto

Maravelez-Acosta, Esmeralda Morales-Tapía, Andrés

Flores-Luna, René Sánchez-de la Luz

Laboratorio de Investigación en Parasitología, Hospital Infantil de México Federico Gómez, México D.F.,México

Introducción. La proteína TMK96 participa en la eritrofagocitosis, es necesaria para la infección intestinal y se localiza en la superficie de $E$. histolytica.

Objetivo. Producir anticuerpos vsTmk96 de Entamoeba histolytica para identificar quistes y trofozoítos en heces diarreicas

Material y métodos. Se determinó la expresión del gen tmk96 y la eritrofagocitosis en las cepas control E. histolytica HM-1 y JK-Mex, por RT-PCR y por el método de bencidina alcalina, respectivamente. El mismo procedimiento se hizo después de pasar los trofozoítos por hígado de hámster. El péptido Tmk96, constituido por 20 aminoácidos, se unió a la proteína acarreadora KLH; con él se inmunizó a un conejo para obtener anticuerpos y purificarlos por cromatografía de afinidad. Se practicó estudio inmunocitoquímico y se reveló con anti-lgG de conejo marcado con biotina-estreptavidina, utilizando el cromógeno 2,2 diaminobencidina.

Resultados. El gen Tmk96 se expresó en las dos cepas patógenas de E. histolytica HM-1 y JK-Mex, y se correlacionó con el porcentaje de eritrocitos fagocitados; en la cepa HM-1 se incrementó $20 \%$ después de pasar por hígado de hámster y la cepa MEXJK-1 permaneció con el $90 \%$ en cultivo y pasados por hígado de hámster. Por cromatografía de afinidad, se obtuvieron $0,1124 \mathrm{mg} / \mathrm{ml}$ de anticuerpos específicos contra la proteína Tmk96, y con ellos, se demostró la presencia de Tmk96 en la superficie de E. histolytica por inmunocitoquímica 
Conclusiones. Se determinó que la proteína Tmk96 tiene relación con $E$. histolytica patógena y puede utilizarse para diagnosticar la presencia de este parásito en heces.

\section{- $\bullet$}

\section{Expresión de ciclofilina de Entamoeba histolytica en el desarrollo del absceso hepático amibiano en el hámster}

Víctor Alberto Maravelez-Acosta, María del Pilar Crisóstomo-Vázquez, Leticia Eligio-García, Moisés

Aceves-Crespo, Andrés Flores-Luna, René Sánchez-de la Luz, Enedina Jiménez-Cardoso

Laboratorio de Investigación en Parasitología, Hospital Infantil de México Federico Gómez, México D.F.,

México

Introducción. Se ha demostrado que Entamoeba histolytica requiere de la presencia de células inmunitarias (linfocitos T, macrófagos y neutrófilos) para el desarrollo del daño en el tejido hepático y esta acción quimioatrayente podría llevarse a cabo por la ciclofilina producida por el parásito y a la que se le ha demostrado la función de citosina.

Objetivo. Evaluar la expresión del gen de la ciclofilina de $E$. histolytica en el desarrollo del absceso hepático amibiano en el hámster y compararla con la expresión de las citocinas IL-4, TNF-a, IFN- $\gamma$ producidas en el bazo del hámster.

Material y métodos. Se formaron 12 grupos de dos hámsters cada uno y se les inoculó por vía $\mathrm{IH}$ trofozoítos de diferentes cepas y aislamientos. Los grupos control fueron E. histolytica HM-1, JK-MEX, medio BR y al cuarto no se le inoculó nada. A los ocho grupos restantes se les inocularon trofozoítos de E. histolytica aislados de muestras de pacientes; cinco días después de la inoculación, se extrajó el $\mathrm{AH}$ y se recuperaron los trofozoítos en medio de Robinson. Se les determinó la expresión de la ciclofilina; paralelamente, se extrajo el bazo para evaluar la expresión de las citosinas IL-4, TNF-a, IFN- $\gamma$ por RT-PCR.

Resultados. Se amplificó una banda de 500 pb en los trofozoítos recién desenquistados, así como en los que desarrollaron el AHA. Se detectó expresión basal de citosinas IL-4, INF- $\gamma$ y TNF-a en el bazo de hámsters inoculados con las cepas control. La ciclofilina presentó una similitud con la expresión de citosinas proinflamatorias (INF- $\gamma$ y TNF-a,) en las muestras de $E$. histolytica obtenidas de pacientes. Conclusiones. La ciclofilina de E. histolytica se expresó durante el desarrollo del absceso hepático amibiano, por lo que sugerimos que puede ser un factor de capacidad patógena, al potenciar la llegada de células inmunitarias (linfocitos T CD4+, macrófagos y neutrófilos) y, con esto, aumentar el daño en el tejido hepático.

\section{Pruebas de la presencia de una posible PMCA en Trypanosoma evansi}

María C. Pérez-Gordones ${ }^{1}$, Vincenza Cervino², Graciela Uzcanga ${ }^{3}$, Marta Mendoza ${ }^{4}$

1 Laboratorio de Fisiología de Membranas, Instituto de Biología

Experimental, Universidad Central de Venezuela, Caracas, Venezuela

2 Laboratorio de Biofísica, Instituto de Biología

Experimental, Universidad Central de Venezuela, Caracas, Venezuela

3 Laboratorio de Biosulfactantes Pulmonares, Instituto de Estudios Avanzados, Caracas, Venezuela

4 Laboratorio de Inmunología de Parásitos, Instituto de Ciencia y Tecnología, USNER

Introducción. La PMCA, enzima involucrada en la homeostasis del $\mathrm{Ca}^{2+}$, ha sido identificada en todas las células eucariotas estudiadas, caracterizándose por su modulación por calmodulina. En tripanosomatidios, se ha demostrado la actividad de esta enzima y su modulación por calmodulina. Sin embargo, el análisis de los genomas de estos parásitos, no determinó la presencia de un dominio de unión a calmodulina en las posible PMCA reportadas.

El objetivo de este trabajo fue demostrar la presencia de una posible PMCA en Trypanosoma evansi y evaluar su modulación por calmodulina.

Materiales y métodos. Partiendo de fracciones de membrana plasmática de $T$. evansi, se procedió a determinar la actividad $\mathrm{Ca}^{2+}$-ATPasa, cuantificando Pi liberado en presencia y ausencia de calmodulina. Posteriormente, se determinó la interacción directa de calmodulina a la enzima, mediante la marcación con calmodulina-biotinilada y su purificación a través de una columna de calmodulina-sefarosa. Mediante PCR y empleando oligos diseñados a partir del gen de una posible PMCA en $T$. brucei, se procedió a identificarla molecularmente.

Resultados. T. evansi presentó actividad $\mathrm{Ca}^{2+}$ ATPasa estimulada por calmodulina. El ensayo de calmodulina biotinilada permitió la obtención de una banda de aproximadamente $120 \mathrm{kDa}$, similar a la obtenida tras la purificación de la enzima mediante una columna calmodulina-sefarosa. Por PCR se pudo identificar un gen cuya traducción comparte alta homología con PMCA descritas en tripanosomatidios. Dicha proteína resultó ser topológicamente similar a PMCA reportadas, 
y presenta 10 dominios transmembrana y los dominios característicos de las bombas de tipo P. Por su parte, ásta no presentó un dominio clásico de unión a calmodulina. Sin embargo, un análisis mediante el servidor "Calmodulin Target Database" permitió predecir un dominio no clásico de unión a calmodulina.

Conclusión. Estos resultados demuestran la presencia de una posible PMCA estimulada por calmodulina en $T$. evansi.

\section{Evidencias fisiológicas, inmunológicas y moleculares de la presencia de un canal de calcio en Trypanosoma evansi}

María Carolina Pérez-Gordones, Graciela Uzcanga, Héctor Rojas, Gustavo Benaim, Marta Mendoza Instituto de Biología Experimental, Universidad Central de Venezuela; Centro de Biofísica y Bioquímica, Instituto Venezolano de Investigaciones Científicas; Biociencias, Instituto de Estudios Avanzados; Instituto de Estudios Científicos y Tecnológicos, Universidad Nacional Experimental Simón Rodríguez, Caracas, Venezuela

Introducción. $\mathrm{El} \mathrm{Ca}^{2+}$ ha sido descrito como un importante segundo mensajero en tripanosomatidios. El aumento en la $\left[\mathrm{Ca}^{2+}\right]_{\mathrm{i}}$ inicia múltiples procesos celulares, bien sea por la liberación de $\mathrm{Ca}^{2+}$ de los depósitos intracelulares o por la entrada a través de canales selectivos, los cuales hasta la fecha no han sido caracterizados en los tripanosomatideos.

El objetivo de este trabajo fue la identificación de un posible canal de $\mathrm{Ca}^{2+}$, usando como modelo Trypanosoma evansi.

Materiales y métodos. Se determinó la concentración de calcio intracelular $\left[\mathrm{Ca}^{2+}\right]_{i}$ en parásitos purificados y cargados con FURA 2AM mediante espectrofluorometría. La marcación inmunoquímico se hizo con fluoróforos, mediante el empleo de anticuerpos específicos y empleando la técnica de microscopía confocal. Se obtuvieron productos de amplificación del ADN por PCR con sondas específicas, diseñadas a partir de la secuencia de un posible canal de calcio encontrado en el genoma de T. brucei.

Resultados. Se registró un aumento en la $\left[\mathrm{Ca}^{2+}\right]_{\mathrm{i}}$, cuando los parásitos se incubaron con tapsigargina, inhibidora de SERCA. El aumento fue mucho mayor en un medio que contiene de $\mathrm{Ca}^{2+}$ que en uno libre de $\mathrm{Ca}^{2+}$, lo cual sugiere un ingreso de $\mathrm{Ca}^{2+}$ al parásito. Este efecto fue notablemente disminuido al emplear 2APB, un inhibidor de canales dependientes del vaciado de reservorios o tipo SOC. Se demostró inmunológicamente un reconocimiento con anticuerpos dirigidos contra canales de $\mathrm{Ca}^{2+}$ en la membrana plasmática, el cual colocaliza con el reconocimiento de los anticuerpos contra tubulina. Finalmente, se obtuvo una secuencia para un putativo canal de calcio, la cual comparte una gran homología con la descrita para $T$. brucei y, mediante su análisis en silico, se identificaron las secuencias asociadas a la región del poro y a las regiones transmembrana características de los canales de calcio.

Conclusión. Estos resultados sugieren la presencia de un canal de calcio en $T$. evansi.

\section{Acanthamoeba spp.: caracterización molecular de aislamientos de muestras humanas en el Laboratorio de Amibiasis, Escuela de Bioanálisis, Universidad Central de Venezuela}

María Vethencourt, Anaibeth Nessi, Raybeth Machado, Carlos Conde, Mónica Galindo, Angelyseb Dorta, Carolina Wagner, Carmen Guzmán, María Pérez Cátedra de Parasitología, Escuela de Bioanálisis, Facultad de Medicina, Universidad Central de Venezuela, Caracas, Venezuela

Introducción. Las amebas de vida libre del género Acanthamoeba afectan al humano y ocasionan enfermedades del sistema nervioso central, ojos y piel. Las especies principalmente implicadas son A. castellani y A. polyphaga. La identificación por examen directo y cultivo requiere tiempo y sólo permite definir el género.

La finalidad de este estudio fue caracterizar molecularmente aislamientos de Acanthamoeba spp. mantenidos en el Laboratorio de Amibiasis, Escuela de Bioanálisis, Universidad Central de Venezuela.

Materiales y métodos. A seis aislamientos de Acanthamoeba spp. de muestras de pacientes (A9, A12, A25 a la A28), cultivados en medio bifásico por 72 horas, se les practicó análisis morfométrico y extracción de ADN (kit Wizard, Promega, USA). La reacción en cadena de la polimerasa $(P C R)$ para género fue estandarizada para amplificar parte del gen que codifica la subunidad ribosómica 18S. La RFLP-PCR se llevó a cabo con Hind I, Hae III y Hha I.

Resultados. Todos los aislamientos se ubicaron en el grupo morfológico II y el producto de la PCR fue de 900 pb. El perfil de digestión obtenido por 
Hind I fue idéntico para todos los aislamientos (560, 194, 126, 79 pb), así como con Hha I (323, 274,232, 80 pb). Con Hae III, los aislamientos A9 y A12 mostraron un perfil de digestión similar (424, 249,156 y 114 pb), a diferencia de los aislamientos A26, A27 y A28 (678,172 y 79 pb). Al comparar los perfiles de digestión con los reportados de cepas de referencia, se definió que $\mathrm{A} 9$ y $\mathrm{A} 12$ corresponden a A. polyphaga y A26, A27 y A28 con A. castellani. A25 mostró un perfil mixto, lo que imposibilitó su definición.

Conclusión. Con la metodología aplicada se logró identificar tanto género como especie de Acanthamoeba de forma rápida y permitirá en el futuro establecer una correlación con las diferentes presentaciones clínicas y la evolución de los pacientes.

\section{Estudio in silico de los genes codificantes para la proteína calcineurina B (CaNB) y calmodulina- ubicuitina (Cub) de tripanosomas}

Marjorie Montenegro ${ }^{1}$, Claudia Cuervo ${ }^{1}$, María del Carmen Thomas², Manuel Carlos López², Concepción

Puerta $^{1}$

1 Laboratorio de Parasitología Molecular, Departamento de Microbiología, Facultad de Ciencias, Pontificia Universidad Javeriana, Bogotá, D.C., Colombia

2 Departamento de Biología Molecular, Instituto de Parasitología y Biomedicina López Neyra, Consejo Superior de Investigaciones Científicas, Granada, España

Introducción. La movilización de calcio intracelular es un mecanismo esencial durante los procesos de invasión e infección celular de Trypanosoma cruzi. Las proteínas calcineurina B (CaNB) y calmodulinaubiquitina (Cub), las cuales contienen dominios de unión a calcio, parecen ser fundamentales en estos procesos. Además, los parásitos mutantes en estas proteínas muestran pérdida de virulencia en modelos de ratón e inhibición de la infección de células HeLa. Como una aproximación a la dilucidación de su función, se comparó la secuencia de nucleótidos y aminoácidos de los genes CaNB y Cub entre diferentes especies de tripanosomas.

Metodología. Con base en las secuencias ortólogas de los genes codificantes para las proteínas calcineurina $B$ y calmodulina-ubiquitina reportados en las bases de datos GenBank y TriTrypDB, se diseñaron dos juegos de oligonucleótidos que permitieron amplificar los genes en el aislamiento colombiano 058PUJ de T. cruzi. Los fragmentos obtenidos se purificaron y clonaron en pGEMßT-
Easy. Las secuencias se compararon con sus ortólogos en $T$. cruzi, $T$. brucei, $T$. vivax y $T$. congolense, mediante el uso de herramientas bioinformáticas.

Resultados. La secuencia de nucleótidos y aminoácidos de calcineurina B y calmodulinaubiquitina de la cepa 058PUJ de $T$. cruzi, mostró ser altamente conservada respecto a sus homólogos en cinco cepas de esta misma especie con identidades de 98 a $99 \%$. Contrario a lo anterior, con los otros tripanosomas se observaron identidades de $64 \%$ para el gen CaNB de T. brucei y $51.4 \%$ para el gen Cub de T. congolense. Sin embargo, en todas las especies las secuencias conservaron los motivos de unión a calcio.

Conclusiones. La alta identidad de estos genes entre distintas cepas de $T$. cruzi sugiere la importancia de su función. Así mismo, los bajos valores de identidad con los tripanosomas africanos pueden ser un reflejo de las diferencias en los ciclos de vida de ambos parásitos.

\section{Sensibilidad al principio activo deltametrina en ninfas de primer y quinto estadio de Pastrongylus geniculatus}

Marlene Reyes, Lyda Esteban, Víctor Manuel Angulo Centro de Investigaciones en Enfermedades Tropicales, Universidad Industrial de Santander, Bucaramanga, Colombia

Introducción. Los piretroides son insecticidas utilizados para el control de triatominos domiciliados. Sin embargo, la intrusión de triatominos silvestres a las viviendas urbanas y rurales requiere la evaluación de las estrategias actuales de control. Por tal motivo, se evaluó la sensibilidad de Pastrongylus geniculatus al principio activo deltametrina en ninfas de primer y quinto estadio.

Metodología. Se aplicó el protocolo de evaluación del efecto insecticida sobre triatominos OMS 1994 adaptado para esta especie, mediante la técnica de aplicación tópica. A partir de una cepa de $P$. geniculatus mantenida en condiciones constantes desde el 2003, se obtuvieron ninfas de primer estadio 24 a 36 horas después de la eclosión, con un peso de $0,85 \pm 0,13 \mathrm{mg}$, y ninfas de quinto estadio con cinco días de ayuno después de la muda y con un peso de 110,62 $\pm 19,24 \mathrm{mg}$. Se calcularon los parámetros estadísticos DL50 y DL99 usando el Probit and logit Analysis Versión 2.0, POLO PLUS. Resultados. En ninfas de primer estadio, la $\mathrm{DL}_{50}$ fue 0,107 ng/insecto (IC $95 \%$; 0,080-0,0143) y la DL fue 4.909 (IC $95 \%$; 2.154-19.192); en las ninfas 
de quinto estadio, la $\mathrm{DL}_{50}$ fue $9.900 \mathrm{ng} /$ insecto (IC $955 ; 8.439-11.385$ ) y la DL99 fue 66.513 (IC $95 \%$; 44.007-137.087).

Conclusiones. La estandarización de la línea base sensible en $P$. geniculatus (cepa UIS) a los insecticidas usados en los programas de control (deltametrina), permite contar con una herramienta que, con parámetros toxicológicos, permita iniciar los estudios de vigilancia de la resistencia en poblaciones de dicho vector.

Financiación. Colciencias, código 110249326216, y Secretaría de Salud de Santander.

$$
\text { - }
$$

\section{Enterocytozoon bieneusi genotypes in dogs in Bogotá, Colombia}

Mónica Santín', Jesús A. Cortés-Vecino², Ronald Fayer

1 Environmental Microbial and Food Safety Laboratory,

Animal and Natural Resources Institute, Agricultural

Research Service, United States Department of

Agriculture, Washington, USA

2 Laboratorio de Parasitología Veterinaria, Universidad

Nacional de Colombia, Bogotá, D.C., Colombia

Enterocytozoon bieneusi was detected in dogs in Bogotá, Colombia, for the first time. Of 120 dogs, $15 \%$ were positive by polymerase chain reaction (PCR). Infected dogs ranged from 2 to 14 years of age, and more male than female dogs were infected with E. bieneusi ( $20 \%$ versus $5 \%$ ). All PCR-positive specimens were sequenced and three genotypes were identified.

A dog-specific genotype (PtEbIX) was identified in feces from 16 dogs. For two dogs, the nucleotide sequences obtained were genetically identical to the $E$. bieneusi Peru 5 and $\mathrm{K}$ genotypes previously reported as human pathogens.

This is the first time that Peru 5 and $\mathrm{K}$ genotypes have been identified in dogs.

This study confirms that dogs are infected with both human pathogenic and host-specific genotypes.

\section{A zoonotic genotype of}

\section{Enterocytozoon bieneusi in horses} Mónica Santín ${ }^{1}$, Jesús A. CortésVecino $^{2}$, Ronald Fayer ${ }^{1}$

1 Environmental Microbial and Food Safety Laboratory, Animal and Natural Resources Institute, Agricultural Research Service, United States Department of Agriculture, Washington, USA

2 Laboratorio de Parasitología Veterinaria, Universidad Nacional de Colombia, Bogotá, D.C., Colombia

This is the first report of Enterocytozoon bieneusi in an equid species. Feces from 195 horses from 4 locations in Colombia were examined for $E$. bieneusi by polymerase chain reaction. Of these, 21 horses (10.8\%) were found positive for $E$. bieneusi. The prevalence of $E$. bieneusi in horses, 1 year of age was significantly higher (23.7\%). No significant differences in prevalence were observed between male (13.7\%) and female horses $(9 \%)$. Sequencing of the internal transcribed spacer region of the SSUrRNA locus identified 3 genotypes. Two genotypes appear to be unique to horses and were named Horse 1 and Horse 2. A third genotype, identified as genotype $D$, was detected in 4 horses. This genotype, previously reported to infect humans, beaver, cattle, dogs, falcons, foxes, macaques, muskrats, pigs, and raccoons, is the most ubiquitous of the E. bieneusi zoonotic genotypes. Our findings indicate that $E$. bieneusi from horses can be a potential source of infection for humans.

\section{Tamandua mexicana (Saussure, 1860) infectada con Trypanosoma rangeli (KP1-) en el municipio de Mompós, zona del Caribe colombiano endémica para la enfermedad de Chagas}

Omar Cantillo-Barraza, Lina Palacio, Edilson Garcés, Omar Triana

Grupo Biología y Control de Enfermedades Infecciosas, Universidad de Antioquia, Medellín, Colombia

Introducción. El conocimiento de huéspedes vertebrados de Trypanosoma rangeli y su comportamiento ecológico, es importante en áreas endémicas para la enfermedad de Chagas, debido a posibles falsos positivos durante el diagnóstico de Tripanosoma cruzi. Mompós (Bolívar, Colombia) es zona endémica para la enfermedad de Chagas, pero hasta la fecha, sin descripción de simpatría para $T$. cruzi y $T$. rangeli.

Objetivos. Reportar la infección de T. mexicana con $T$. rangeli en el municipio de Mompós.

Materiales y métodos. Un espécimen macho de $T$. mexicana fue capturado en una zona urbana de Mompós, con reportes de infestación con triatominos. Se obtuvieron $0,3 \mathrm{ml}$ de sangre tras sedación del individuo y se cultivaron en medio NNN con $1 \mathrm{ml}$ de LIT al $10 \%$ SBF. El cultivo se revisó cada siete días hasta ver flagelados. Para la identificación molecular de la especie del aislamiento, se utilizaron los iniciadores TCZF y TCZR que amplifican el ADN satélite de T. cruzi, así como los iniciadores D75 y D76 que amplifican la región divergente Da7 del ARNr en $T$. cruzi y $T$. 
rangeli, y los iniciadores TrF3 y TrR8 específicos para $T$. rangeli. Para la caracterización del grupo (KP1, KP2 y KP3) de $T$. rangeli, se emplearon los iniciadores S35, S36 y KP1L.

Resultados. Tamandua mexicana (oso hormiguero de chaleco) es una especie silvestre, cuya presencia en el área urbana es consecuencia del desplazamiento de fauna, ocurrido durante las inundaciones en la zona en el 2010 y comienzo del 2011. La cepa aislada de este reservorio fue caracterizada molecularmente como $T$. rangeli con un perfil KP1-.

Conclusión. Este es el primer reporte de infección de $T$. mexicana con $T$. rangeli para Colombia. La presencia de $T$. rangelien una zona con transmisión de $T$. cruzi debe considerarse para el diagnóstico de la enfermedad de Chagas en la zona.

\section{-. \\ Reconocimiento de la proteína HSP70 de Trypanosoma rangeli por linfocitos T CD8 ${ }^{+}$de pacientes con enfermedad de Chagas}

Paola Lasso ${ }^{1}$, Claudia Cuervo ${ }^{1}$, Adriana Cuéllar², Fernando Rosas ${ }^{3}$, Víctor Velasco ${ }^{3}$, María del Carmen Thomas ${ }^{4}$, Manuel Carlos López ${ }^{4}$, John Mario González ${ }^{5}$, Concepción Judith Puerta

${ }^{1}$ Laboratorio de Parasitología Molecular, Pontificia Universidad Javeriana, Bogotá, D.C., Colombia

2 Grupo de Inmunobiología y Biología Celular, Pontificia Universidad Javeriana, Bogotá, D.C., Colombia

${ }^{3}$ Fundación Clínica Abood Shaio, Bogotá, D.C., Colombia

4 Instituto de Parasitología y Biomedicina López Neyra, Consejo Superior de Investigaciones Científicas, Granada, España

${ }^{5}$ Grupo de Ciencias Básicas Médicas, Facultad de Medicina, Universidad de los Andes, Bogotá, D.C., Colombia

Introducción. Trypanosoma rangelies un protozoo que infecta vertebrados e insectos en América. A pesar de no ser patógeno para el vertebrado, su estudio es relevante debido a la estrecha relación evolutiva y la reacción inmunológica cruzada con $T$. cruzi. Además, estos parásitos comparten reservorios, vectores, y zonas geográficas, y han sido reportados en infecciones mixtas, aspectos que complican el diagnóstico y la epidemiología de la enfermedad de Chagas. También, varios estudios sugieren que $T$. rangeli confiere protección contra cepas virulentas de T. cruzi en modelos animales. Con base en lo anterior, se evaluó la respuesta de linfocitos $\mathrm{T}(\mathrm{LT}) \mathrm{CD}^{+}$frente al estímulo con la proteína HSP70 de $T$. rangeli en individuos infectados con T. cruzi.

Materiales y métodos. Se evaluaron 10 individuos infectados con $T$. cruzi con diferentes grados de la enfermedad y 5 individuos negativos para la infección. Se obtuvieron células mononucleares de sangre periférica de cada individuo, se estimularon con las proteínas HSP70 recombinantes de T. cruzi - $T$. rangeli y se colorearon con los anticuerpos anti-CD3, anti-CD8 y anti-IFN $\square$. Los datos se adquirieron con el citómetro de flujo FACSCanto II y se analizaron con el programa FlowJo v7.2.5.

Resultados. La producción de IFN $\square$ se detectó en LT CD8 ${ }^{+}$estimulados con la proteína HSP70 de $T$. rangeli en 5 de 10 individuos infectados (media \pm desviación estándar: 0,13 $\pm 0,16 \%$ ), con un rango de 0,08 a $0,43 \%$, y en LT CD8 ${ }^{+}$estimulados con la proteína HSP70 de T. cruzi en 6 de 10 individuos infectados (media \pm desviación estándar: $0,15 \pm 0,21 \%$, con un rango de 0,07 a $0,71 \%$. No se encontraron diferencias estadísticamente significativas en las frecuencias de IFN $\square$ con los dos estímulos ( $p>0,05)$.

Conclusiones. LOS LT CD8 ${ }^{+}$de pacientes con enfermedad de Chagas responden frente a la proteína HSP70 de $T$. rangeli produciendo IFN $\square$, lo cual sugiere que esta proteína puede estar involucrada en la reacción inmunológica cruzada entre ambas especies.

\section{-}

\section{Genotipificación de aislamientos axénicos colombianos de Giardia intestinalis}

Paula C. Hernández, Jacqueline Chaparro-Olaya Laboratorio de Parasitología Molecular, Universidad EI Bosque, Bogotá, D.C., Colombia

Introducción. Giardia intestinalis es un parásito protozoario flagelado que habita el intestino delgado del hombre y otros mamíferos, causando una enfermedad conocida como giardiasis. Giardia intestinalis se clasifica en diversos grupos genéticos que se sospecha tienen relación con el huésped que infectan y con las manifestaciones clínicas de la enfermedad. Esto hace necesario estudiar los diferentes genotipos de este parásito que circulan en la comunidad.

En Colombia no se han hecho estudios moleculares para analizar la diversidad genética de las poblaciones de Giardia; por tanto, nuestro estudio pretende contribuir al conocimiento de los genotipos circulantes de $G$. intestinalis en nuestro país.

Materiales y métodos. El ADN de los aislamientos 
de Giardia usados en este estudio, fue descrito anteriormente por Ravid en 2007. Este ADN provenía de cultivos de trofozoítos que se obtuvieron a partir de quistes aislados de pacientes y exquistados in vivo en gerbils. Se pracricó PCR-RFLP del gen glutamato deshidrogenasa $y$, además, los productos de PCR se secuenciaron.

Resultados. El patrón de restricción mostrado en todos los aislamientos fue idéntico al de referencia WBC6 perteneciente al ensamblaje A, de subtipo I. Todos los aislamientos axénicos muestreados de Giardia pertenecen al ensamblaje Al. Estos resultados se corroboraron con los obtenidos por secuenciación.

Conclusiones. A pesar de la homogeneidad genética de los aislamientos examinados en este estudio, estos provienen de un grupo heterogéneo de individuos (niños y adultos, hombres y mujeres, con síntomas y asintomáticos). Esto sugiere que hay factores del huésped o factores de virulencia asociados al parásito, que controlan las manifestaciones clínicas de la infección y que no podemos detectar por medio de la genotipificación, en este caso, de parásitos de Giardia pertenecientes al ensamblaje Al.

\section{Identificación y caracterización de los genes codificantes para la nitrorreductasa de tipo I de Trypanosoma rangeli}

Silvia Duarte ${ }^{1}$, Claudia Cuervo ${ }^{1}$, María del Carmen Thomas², Manuel Carlos López ${ }^{2}$, Concepción Puerta ${ }^{1}$

1 Laboratorio de Parasitología Molecular, Departamento de Microbiología, Facultad de Ciencias, Pontificia Universidad Javeriana, Bogotá, D.C., Colombia

2 Departamento de Biología Molecular, Instituto de Parasitología y Biomedicina López Neyra, Consejo Superior de Investigaciones Científicas, Granada, España

Introducción. La actividad de la proteína nitrorreductasa de tipo I (NTR) ha sido reportada como fundamental para el crecimiento de epimastigotes y su posterior transformación a tripomastigotes metacíclicos. Trypanosoma rangeli es un parásito no patógeno que infecta mamíferos en América. El ciclo de vida de $T$. rangelien el huésped mamífero es poco conocido. Sin embargo, los estudios en animales y cultivos celulares sugieren que $T$. rangeli, a diferencia de Trypanosoma cruzi, no invade de forma productiva las células. Por tanto, $T$. rangeli constituye un modelo de estudio para la búsqueda de funcionalidad de las proteínas ortólogas a las de $T$. cruzi que puedan estar involucradas en los procesos de interacción huésped-parásito.

Metodología. Con base en las secuencias ortólogas de los genes codificantes para nitrorreductasa reportados en las bases de datos GenBank y TriTrypDB, se diseñó un juego de oligonucleótidos que permitió amplificar un fragmento de 900 pb en el aislamiento colombiano Tre de T. rangeli. Dicho fragmento se purificó y clonó en pGEM®T-Easy. Las secuencias obtenidas se analizaron haciendo uso de herramientas bioinformáticas para su caracterización.

Resultados. Se obtuvo una secuencia de $890 \mathrm{pb}$, con una identidad de $71,9 \%$ con los ortólogos de T. cruzi, de 57,9\% con T. brucei y de $46,9 \%$ con $T$. brucei gambiense. Dicho gen codifica una proteína de 296 aminoácidos con peso molecular de 32,4 $\mathrm{kDa}$ y presencia de los dominios característicos de esta familia de proteínas. Al compararla con otros tripanosomas, revela identidades de $67 \%$ con $T$. cruzi, y $56 \%$ con $T$. brucei y $T$. brucei gambiense. Conclusión. A pesar de las diferencias encontradas entre las proteínas de la nitrorreductasa de tripanosomas, éstas conservan sus dominios catalíticos; por tanto, se espera que dichas proteínas tengan una función similar en estos microorganismos. 